\title{
Factors affecting the incidence of postoperative periprosthetic fractures following primary and revision hip arthroplasty: a systematic review and meta- analysis
}

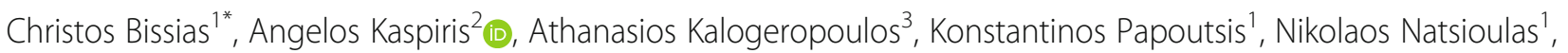
Konstantinos Barbagiannis ${ }^{1}$, Panayiotis J. Papagelopoulos ${ }^{4}$ and Olga D. Savvidou ${ }^{4}$

\begin{abstract}
Objectives: The increasing number of hip arthroplasties (HA), due to the growing elderly population, is associated with the risk of femoral periprosthetic fractures (FPFs). The purpose of this study was to identify potential risk factors for the development of FPFs after HA.

Methods: A systematic review was conducted in five data bases (Medline, Embase, Cochrane, Cinahl, ICTRP) according to the Preferred Reporting Items for Systematic reviews and Meta-analysis (PRISMA) guidelines up to May 2019, using the key words "risk factor," "periprosthetic fracture," and "hip replacement or arthroplasty." Meta-analysis of the clinical outcomes of HA and subgroup analysis based on the factors that were implicated in FPFs was performed.
\end{abstract}

Results: Sixteen studies were included (sample size: 599,551 HA patients, 4253 FPFs, incidence 0.71\%). Risk factors statistically associated with increased incidence of FPFs were female gender $(+40 \%)$, previous revision arthroplasty surgery ( $\times 3$ times), and the presence of rheumatoid arthritis $(\times 2.1$ times), while osteoarthritis $(-57 \%)$, cement application $(-59 \%)$, and insertion of Biomet $(-68 \%)$ or Thompson's prosthesis $(-75 \%)$ were correlated with low prevalence of FPFs. Obesity, cardiac diseases, advanced age, bad general health (ASA grade $\geq 3$ ), and use of Exeter or Lubinus prosthesis were not linked to the appearance of FPFs.

Conclusion: This meta-analysis suggested that female gender, rheumatoid arthritis, and revision arthroplasty are major risk factors for the development of FPFs after a HA. In those patients, frequent follow-ups should be planned. Further prospective studies are necessary to clarify all the risk factors contributing to the appearance of FPFs after HA.

Keywords: Risk factors, Periprosthetic fractures, Hip arthroplasty

\footnotetext{
* Correspondence: chrisbis@hotmail.com

'Department of Orthopaedic Surgery, Naval Hospital of Athens, Deinokratous

70, 11521 Athens, Greece

Full list of author information is available at the end of the article
}

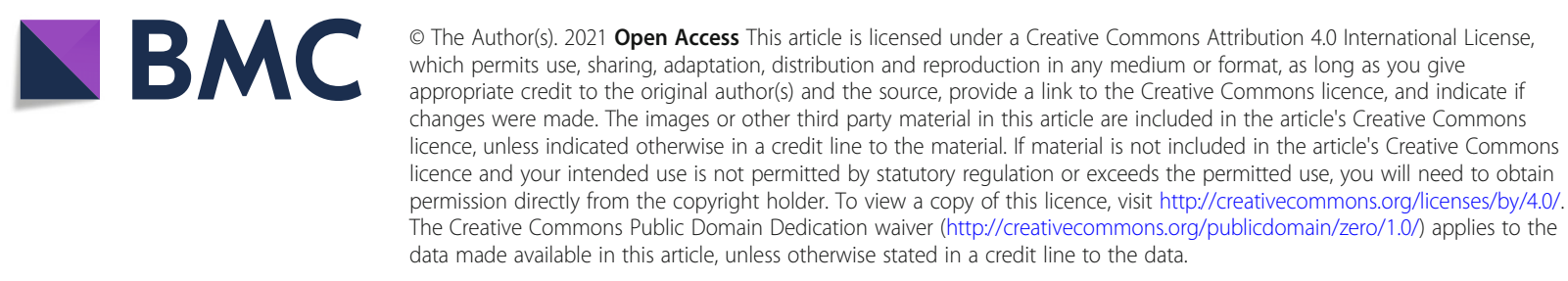




\section{Introduction}

Femoral periprosthetic fractures (FPFs) after total hip arthroplasty (THA) were first described by Horwitz and Lenobel in 1954 [1]. FPFs constitute a devastating complication that often results in poor clinical outcome. Diagnosis of FPFs is typically made by the combination of clinical appearance, history of injury, and conventional radiographic examination. The widely used Vancouver classification provides a reliable evaluation of FPFs based on the femoral anatomic location of the fracture and the presence of a well-fixed or loose component [1]. The incidence of FPFs after hip arthroplasties (HA) has been reported between 0.045 and $4.1 \%$ [2-4]. The increasing prevalence of FPFs is directly associated with the increasing frequency of primary or revision HAs [5].

Although FPFs were not correlated with a specific implantation procedure, it was reported that they occurred more frequently after the application of cementless HA [6]. Factors that also contributed to the development of FPFs were the (a) low preoperative quality of patients' bone stock like osteolytic or osteoporotic defects, (b) accompanied reduced mechanical properties of the implant surrounding tissue, (c) absence of stability of the implanted prosthesis, and (d) presence of pericapsular pathological changes [5]. Furthermore, patients with increased age, poor American Society of Anaesthesiologists (ASA) score, dementia, limited mobilization, partial weight bearing, and substantive functional limitations during postoperative period appeared to have a much higher risk for FPFs, implant failure, and mortality [6]. FPFs after primary HA resulted following spontaneous or low-energy injury corresponding to $8 \%$ or $75 \%$, respectively $[7,8]$. Treatment and postoperative rehabilitation of these fractures are complicated and expensive and correlate to increased morbidity and mortality. Specifically, the mortality rate after FPFs was remarkably increased in patients who had undergone primary joint replacement corresponding to $11 \%$ during the first year post-operatively. We must highlight the fact that a delay greater than 2 days from admission to the time of surgery also increased the mortality rate at one year [9].

Therefore, it is crucial to determine the potential risk factors that are associated with FPFs after total HA and hemiarthroplasty. Identification of risk factors for FPFs not only bridges the gap between clinical and basic or translational science but also improves the surgical practice in operating room as surgeons may incorporate novel concepts in their surgical techniques [10, 11]. Furthermore, in complex surgical problems, like FPFs, it is deemed necessary to understand the disease process and to integrate new scientific findings [12]. However, literature regarding the qualitative analysis of the identification of such risk factors is limited and does not provide adequate evaluation of their impact on clinical practice. Moreover, the majority of the studies included qualitative synthesis of limited sample size and/or number of surveys $[13,14]$ and/or potential risk factors [15].

Despite the fact that multiple identified risk factors for FPF have been described in the international literature including older age, female sex, bone fragility disorders, and systematic diseases $[5,6]$, there is a lack of a comprehensive study with generalized statistics analyzing the association between FPF and risk factors in both primary and revision HA. The aim of our systematic review and meta-analysis was to provide an up-to-date summary of the incidence and odds ratio of FPFs after performing primary and revision HA and to establish the contribution of potential risk factors in the development of FPFs.

\section{Materials and methods}

This study was performed according to the Preferred Reporting Items for Systematic Reviews and MetaAnalyses (PRISMA) guidelines [16]. PRISMA checklist was used for reporting of relevant items for this metaanalysis and was provided in the supplementary document (Supplementary Table 1) [16].

\section{Literature search}

A systematic computer-based literature review search with predefined criteria was attained on 08 May 2019 in the following databases: PubMed (1947 to present), Cochrane Database of Systematic Reviews (1992 to present), Embase (1974 to present), Cinahl, and WHO International Clinical Trials Registry platform (ICTRP). Research methodology was based on the combination of the following terms: "factors [All Fields]," "risk [All Fields]," "periprosthetic fractures [All Fields]," and "hip replacement, hemiarthroplasty or arthroplasty [All Fields]." The entire electronic literature search was conducted independently by two authors (CB and ODS) and an experienced clinical librarian. Moreover, the two senior authors (CB and ODS) screened the titles and abstracts independently in order to identify studies examining the clinical outcomes after the application of HA. If there was a disagreement between them, the final decision was made by the senior author.

\section{Study eligibility}

Studies that examined the risk factors, the outcome, and the incidence of post-operative FPFs after performing HA were identified. HA was defined as the replacement of all or part of the hip joint by a prosthetic implant [17]. FPFs were defined as the femoral fractures that took place above, below, or close to an implanted prosthesis stem [18]. Only full-text articles were eligible for inclusion. The inclusion criteria were (a) studies written in English language, (b) comparative studies assessing 
the application of primary and revision hip arthroplasties, (c) surveys concerning HA that were performed in human subjects, and (d) data on the risk factors for FPFs and the outcome should have been clearly given for each patient. No publication date limitations there were set.

Studies that examined primary or metastatic hip cancers treated with HA, or surveys without comparative results, or being written in a language other than English were excluded. Case reports, reviews, letters to the editor, expert opinions articles, studies concerning PFs of acetabulum, research with insufficient details about the type of intervention, the clinical outcome, and surveys without obtainable data, were excluded.

\section{Data extraction}

All data of each study was assembled in a Microsoft Excel spreadsheet, classified per intervention and type of periprosthetic fracture. Characteristics extracted from clinical studies included authorship, publication year, study design (cohort or randomized control trial), single or multicenter status, enrolled sample number, population gender and age, and risk factors in both control and treatment groups, HA procedure, outcomes regarding the frequency of periprosthetic fracture development, and the type of HA. Data from each study are summarized in Table 1.

Two reviewers (CB and ODS) examined all the identified surveys and extracting data by using a predetermined form. The presence of duplicate studies was examined using Endnote software (Clarivate Analytics, Philadelphia, Pennsylvania, USA).

\section{Study selection and quality assessment}

The methodology of each study was assessed independently by the two senior authors (CB and ODS) using the Newcastle-Ottawa quality assessment scale [35]. Included studies were graded according to a threecategory scale. Surveys that appeared a total score of 0 $3,4-6$, and 7-9 were classified to be of a poor, fair, or good quality, respectively (Table 2a). Modified Jadad scale for clinical trials was also used to evaluate the quality of included trials [36]. Jadad score greater than 4 was considered to be of high quality (Table 3). There were not exclusion criteria for age, population, diagnosis, or quality of the studies. Funnel plots were built in order to determine the aspect of publication bias that may affect the conclusions of our analysis.

\section{Statistical analysis}

This meta-analysis was conducted in line with the recommendations from Cochrane and PRISMA statement [16]. Statistical analysis was performed with the STATA Statistical software, version 11.0 (Stata Corp LLC, College Station, TX, USA). The incidence of FPFs after the application of HAs, the correlated risk factors and the odds ratios (ORs), and the associated 95\% confidence intervals $(95 \% \mathrm{CI})$ were calculated. Heterogeneity between the trials was calculated by using Cochrane $Q$ and the inconsistency $\left(I^{2}\right)$ test. The degree of heterogeneity was graded as low $\left(I^{2}<25 \%\right)$, moderate $\left(I^{2}\right.$ from 25 to $\left.75 \%\right)$, and high $\left(I^{2}>75 \%\right)$. A random effect model was used to calculate pooled ORs in the case of significant heterogeneity, while the fixed effect model was used in the studies with low heterogeneity. This was undertaken because in sensitivity analysis the presentation of both models provides comprehensive evaluation of how differences in datasets affected the observed outcomes [37]. Egger's test and graphical exploration with funnel plots were used to evaluate the risk of publication bias. The level of statistical significance was defined as $p<0.05$.

\section{Results \\ Study characteristics}

In the initial search, a total of 126 relevant trials were detected. After the initial evaluation of the studies based on the abstract and title, 103 publications were included. The further analysis of the remaining papers resulted in the exclusion of 104 surveys. Twenty-eight studies were excluded due to inadequate methodology, while 49 studies were declined being statistically unsatisfactory. Moreover, 13 studies examined acetabular PFs, 3 were written in other language than English and 11 surveys were not original studies and were analyzed in the flowchart of Fig. 1.

Finally, sixteen studies published between 2003 and 2018 met our inclusion criteria for the analysis of potential risk factors for the development of FPFs after THA [19-34]. The grade of the agreement among the reviewers that evaluated the scientific quality of the included studies was strong. The main characteristics of the included participants are displayed in the Table 1.

\section{Quality assessment}

In Tables 2 and 3, the methodological quality of the enrolled studies is summarized. According to the NewcastleOttawa scale and the modified Jadad score, all the enrolled trials were considered being of good and high quality and, therefore, were judged to be at a low risk of bias.

Furthermore, funnel plots were created to evaluate publication bias. After this evaluation, all studies were found to lie within a $95 \% \mathrm{CI}$ as represented by the inverted funnel, suggesting absence of publication bias.

\section{Outcomes}

In total, 599.677 HA were included in the meta-analysis. Fourteen studies were used to reveal the prevalence of FPFs [20, 22-34], as two of the studies were characterized as case-control surveys $[19,21]$ and were excluded of prevalence calculation. Finally, 599.551 HA and 4253 
Table 1 Clinical characteristics of studies included in the meta-analysis

\begin{tabular}{|c|c|c|c|c|c|c|c|}
\hline & Author, year & Country & Type of study & $\begin{array}{l}\text { Number } \\
\text { of } \\
\text { patients }\end{array}$ & $\begin{array}{l}\text { Number of } \\
\text { periprosthetic } \\
\text { fractures }\end{array}$ & $\begin{array}{l}\text { Follow-up } \\
\text { period (in } \\
\text { months) }\end{array}$ & Risk factors \\
\hline 1 & $\begin{array}{l}\text { Sarvilinna et al. } \\
\text { [19] }\end{array}$ & Finland & $\begin{array}{l}\text { Prospective } \\
\text { cohort study }\end{array}$ & 31599 & 1555 & 144 & $\begin{array}{l}\text { Gender, prosthesis type, and age without } \\
\text { significance as risk factors, Risk of PF was } \\
\text { about the same in patients operated with } \\
\text { or without the cemented prosthesis }\end{array}$ \\
\hline 2 & $\begin{array}{l}\text { Sarvilinna et al. } \\
\text { [20] }\end{array}$ & Finland & $\begin{array}{l}\text { Cases control } \\
\text { study }\end{array}$ & 31 & 31 & $N / A^{*}$ & $\begin{array}{l}\text { Fracture as the primary diagnosis, } \\
\text { Protective factors: cemented prosthesis, } \\
\text { Thompson prosthesis, and Biomet prosthesis, } \\
\text { and they were associated with increased } \\
\text { incidence of loosening of femoral component } \\
\text { and reduced incidence of infection and } \\
\text { dislocation }\end{array}$ \\
\hline 3 & $\begin{array}{l}\text { Sarvilinna et al. } \\
\text { [21] }\end{array}$ & Finland & $\begin{array}{l}\text { Cases control } \\
\text { study }\end{array}$ & 48 & 16 & $N / A^{*}$ & $\begin{array}{l}\text { Young age at the time of the hip fracture } \\
\text { and polished wedge type of prosthesis, } \\
\text { Protective factors: Thompson prosthesis } \\
\text { and Biomet prosthesis }\end{array}$ \\
\hline 4 & Berend et al. [22] & USA & $\begin{array}{l}\text { Prospective } \\
\text { cohort study }\end{array}$ & 2551 & 59 & 81 & $\begin{array}{l}\text { Anterolateral approach, uncemented femoral } \\
\text { fixation, and female sex, Protective factors: } \\
\text { cemented prostheses but they were associated } \\
\text { with reduced femoral component survivorship }\end{array}$ \\
\hline 5 & Cook et al. [23] & U.K. & $\begin{array}{l}\text { Case-control } \\
\text { study }\end{array}$ & 6334 & 124 & 204 & $\begin{array}{l}\text { Patients older than } 70 \text { years, cemented } \\
\text { arthroplasties }\end{array}$ \\
\hline 6 & Meek et al. [24] & U.K. & $\begin{array}{l}\text { Prospective } \\
\text { cohort study }\end{array}$ & 51628 & 508 & 60 & Female gender, age $>70$ and revision arthroplasty \\
\hline 7 & Zhang et al. [25] & China & $\begin{array}{l}\text { Retrospective } \\
\text { cohort study }\end{array}$ & 424 & 26 & $N / A^{*}$ & $\begin{array}{l}\text { Cemented and revision arthroplasties, osteoporosis, } \\
\text { and previous fracture }\end{array}$ \\
\hline 8 & Savin et al. [26] & Romania & $\begin{array}{l}\text { Retrospective } \\
\text { cohort study }\end{array}$ & 3574 & 47 & $\mathrm{~N} / \mathrm{A}^{*}$ & $\begin{array}{l}\text { Cementless and revision arthroplasties, Protective } \\
\text { factors: cemented prosthesis }\end{array}$ \\
\hline 9 & Singh et al. [27] & USA & $\begin{array}{l}\text { Prospective } \\
\text { cohort study }\end{array}$ & 5951 & 330 & 67 & $\begin{array}{l}\text { Female gender, high Deyo-Charlson comorbidity } \\
\text { index, and revision arthroplasties }\end{array}$ \\
\hline 10 & Singh et al. [28] & USA & $\begin{array}{l}\text { Prospective } \\
\text { cohort study }\end{array}$ & 13760 & 305 & 75 & $\begin{array}{l}\text { Female gender, high Deyo-Charlson comorbidity } \\
\text { index, ASA score } \geq 2 \text {, and cemented arthroplasties }\end{array}$ \\
\hline 11 & Katz et al. [29] & USA & $\begin{array}{l}\text { Prospective } \\
\text { cohort study }\end{array}$ & 31443 & 215 & 156 & Older age and female gender \\
\hline 12 & Thien et al. [30] & Sweden & $\begin{array}{l}\text { Prospective } \\
\text { cohort study }\end{array}$ & 436861 & 768 & 24 & $\begin{array}{l}\text { Shape and surface finish of the femoral stem and } \\
\text { cemented arthroplasties, Protective factors: cemented } \\
\text { prostheses but they were associated with higher risk } \\
\text { of FPFs in male compared with female patients }\end{array}$ \\
\hline 13 & Ricioli Jr et al. [31] & Brazil & $\begin{array}{l}\text { Retrospective } \\
\text { cohort study }\end{array}$ & 1771 & 101 & 180 & $\begin{array}{l}\text { Female gender aged } \geq 65 \text { years, presence of a } \\
\text { previous hip surgery, and revision arthroplasties }\end{array}$ \\
\hline 14 & Gromov et al. [32] & Denmark & $\begin{array}{l}\text { Retrospective } \\
\text { cohort study }\end{array}$ & 1550 & 48 & 24 & $\begin{array}{l}\text { Bone morphology (femoral Dorr type C), female } \\
\text { gender, and cementless prosthesis }\end{array}$ \\
\hline 15 & $\begin{array}{l}\text { Lindberg-Larsen } \\
\text { et al. [33] }\end{array}$ & Denmark & $\begin{array}{l}\text { Prospective } \\
\text { cohort study }\end{array}$ & 7019 & 150 & 03 & $\begin{array}{l}\text { Uncemented femoral stem, medically treated } \\
\text { osteoporosis, female sex, and older age, Protective } \\
\text { factors: cemented prosthesis }\end{array}$ \\
\hline 16 & Tamaki et al. [34] & Japan & $\begin{array}{l}\text { Retrospective } \\
\text { cohort study }\end{array}$ & 833 & 17 & 03 & Short stem length and cementless prosthesis \\
\hline
\end{tabular}

*Not applicable

FPFs femoral periprosthetic fractures

FPFs were reported, demonstrating prevalence of $0.71 \%$. In specific, the reported cases between 2003 and 2013 corresponded to incidence of $2.4 \%$, whereas the prevalence of FPFs between 2014 and 2018 was reduced to $0.27 \%$ (Fig. 2).

\section{Epidemiological risk factors}

Thirteen studies [20-25, 27-29, 31-34] analyzed gender as a risk factor for the development of femoral PFs after HA. Meta-analysis of these studies $\left(Q=27.4, I^{2}=56.2 \%\right.$, $P=0.007)$ revealed that female gender was as much as 


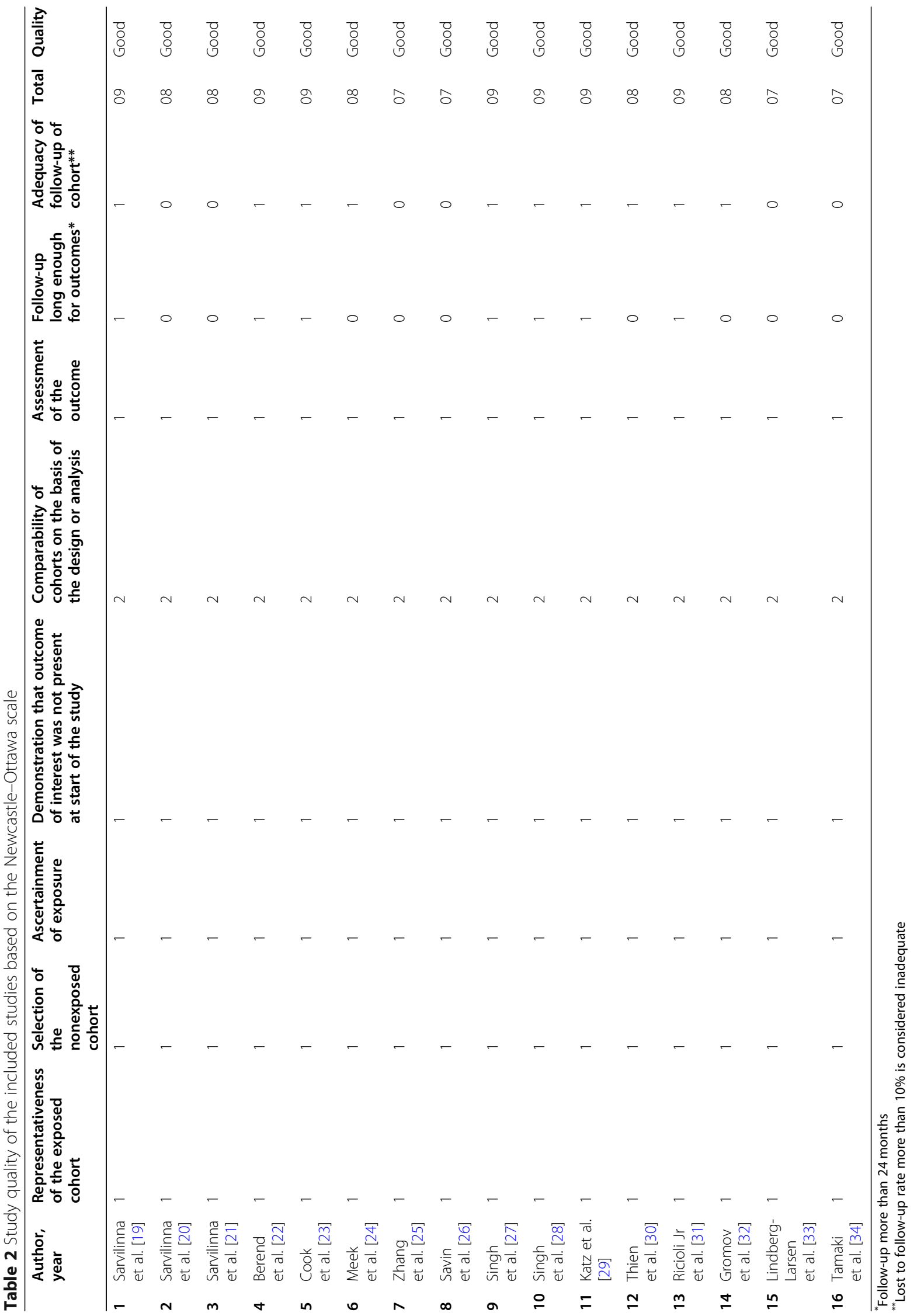


Table 3 Study quality of the included studies based on the modified Jadad scale

\begin{tabular}{|c|c|c|c|c|c|c|c|}
\hline & Author, year & Randomization & $\begin{array}{l}\text { Concealment } \\
\text { of allocation }\end{array}$ & $\begin{array}{l}\text { Double } \\
\text { blinding }\end{array}$ & $\begin{array}{l}\text { Total withdrawals } \\
\text { and dropouts }\end{array}$ & Total & Quality \\
\hline 1 & Sarvilinna et al. [19] & $* *$ & * & $*$ & $* *$ & 06 & Good \\
\hline 2 & Sarvilinna et al. [20] & * & * & * & * & 04 & Good \\
\hline 3 & Sarvilinna et al. [21] & * & * & * & * & 04 & Good \\
\hline 4 & Berend et al. [22] & $* *$ & * & * & $* *$ & 06 & Good \\
\hline 5 & Cook et al. [23] & $* *$ & * & * & * & 05 & Good \\
\hline 6 & Meek et al. [24] & $* *$ & * & * & $* *$ & 06 & Good \\
\hline 7 & Zhang et al. [25] & * & * & * & * & 04 & Good \\
\hline 8 & Savin et al. [26] & * & * & * & * & 04 & Good \\
\hline 9 & Singh et al. [27] & $* *$ & * & * & $* *$ & 06 & Good \\
\hline 10 & Singh et al. [28] & $* *$ & * & * & $* *$ & 06 & Good \\
\hline 11 & Katz et al. [29] & $* *$ & * & * & $* *$ & 06 & Good \\
\hline 12 & Thien et al. [30] & $* *$ & * & * & $* *$ & 06 & Good \\
\hline 13 & Ricioli Jr et al. [31] & * & * & * & * & 04 & Good \\
\hline 14 & Gromov et al. [32] & * & * & * & * & 04 & Good \\
\hline 15 & Lindberg-Larsen et al. [33] & ** & * & * & $* *$ & 06 & Good \\
\hline 16 & Tamaki et al. [34] & * & * & * & * & 04 & Good \\
\hline
\end{tabular}

40\% more likely to sustain FPFs (OR: 1.40, 95\% CI: $1.15-1.64, p<0.001$ ) (Fig. 3).

Five studies [20, 23, 27-29] and six studies [20, 23, 24, $27,28,32]$ reported age greater than 80 years and 70 years as a risk factor, respectively. Meta-analysis of these studies $\left(Q=18.4, I^{2}=78.2 \%, P=0.765\right.$, and $Q=59.1, I^{2}$ $=91.5 \%, P=0.001$, respectively) revealed that age (older than 80 and 70 years) was not a significant risk factor for the development of FPFs (OR: 1.36, 95\% CI: 0.79-1.94, $p$ $=0.249$, and OR: $1.31,95 \%$ CI: 0.82-1.81, $p=0.351$, respectively).

Obesity was examined as a risk factor for FPF appearance in four surveys [27, 28, 32, 33]. Meta-analysis of these trials $\left(Q=0.17, I^{2}=0.0 \%, p=0.982\right)$ demonstrated that obesity was not an important risk factor associated with increased frequency of FPFs (OR: 0.90, 95\% CI: $0.76-1.03, p=0.164$ ).

\section{General medical condition risk factors}

In three studies [21, 27, 28], general health status of the patients who underwent $\mathrm{HA}$ was evaluated with the ASA Physical Status Classification System. However, meta-analysis of these studies $\left(Q=11.3, I^{2}=81.9 \%, p=\right.$ 0.001 ) did not identify the ASA score $\geq 3$ as statistically significant risk factor for FPF appearance (OR: 0.47, 95\% CI: $0.43-1.31, p=0.731)$.

Similarly, meta-analysis $\left(Q=4.56, I^{2}=56.1 \%, p=\right.$ $0.102)$ of three studies [21, 28, 29], which explored preexisting cardiac disease as a risk factor for FPF development, showed that heart pathology was not associated with increased incidence of FPFs (OR: 1.00, 95\% CI: $0.65-1.36, p=0.289)$.

\section{Joint diseases risk factors}

Meta-analysis ( $Q=2.0, I^{2}=0.0 \%, p=0.573$ ) of four surveys $[20-22,28]$ that included the examination of rheumatoid arthritis (RA) as a risk factor for PFs demonstrated that RA is a remarkable risk factor contributing in FPF development. Specifically, patients with RA who underwent HA had 2.1 times greater risk to experience FPFs (OR: 2.1, 95\% CI: 1.05-3.15, $p=0.009$ ) (Fig. 4).

Meta-analysis $\left(Q=2.06, I^{2}=2.09 \%, p=0.357\right)$ of three studies $[20,22,28]$ that reviewed osteoarthritis (OA) as potential factor implicated in FPF evolvement revealed that OA was negatively associated with the appearance of FPFs. Indeed, patients with OA had 57\% reduced risk to experience FPFs (OR: 0.43, 95\% CI: 0.32-0.54, $p=$ 0.010) (Fig. 5).

\section{Fixation and implant type risk factors}

In five studies [21, 24, 26, 29, 31], the presence of a revision $\mathrm{HA}$ was reported. Meta-analysis $\left(Q=51.3, I^{2}=\right.$ $91.2 \%, p<0.001)$ of these studies identified that the risk of FPFs after revision HA is 3 times higher than primary HA (OR: 3.05, 95\% CI: 1.27-4.82, $p=0.005$ ) (Fig. 6).

In seven studies [19, 20, 22, 26, 28, 30, 33], the application of cemented prosthesis was presented. Metaanalysis of these surveys $\left(Q=286.4, I^{2}=97.9 \%, p=\right.$ 0.001 ) confirmed that the use of cemented femoral prosthesis was a significant protective factor, decreasing the 


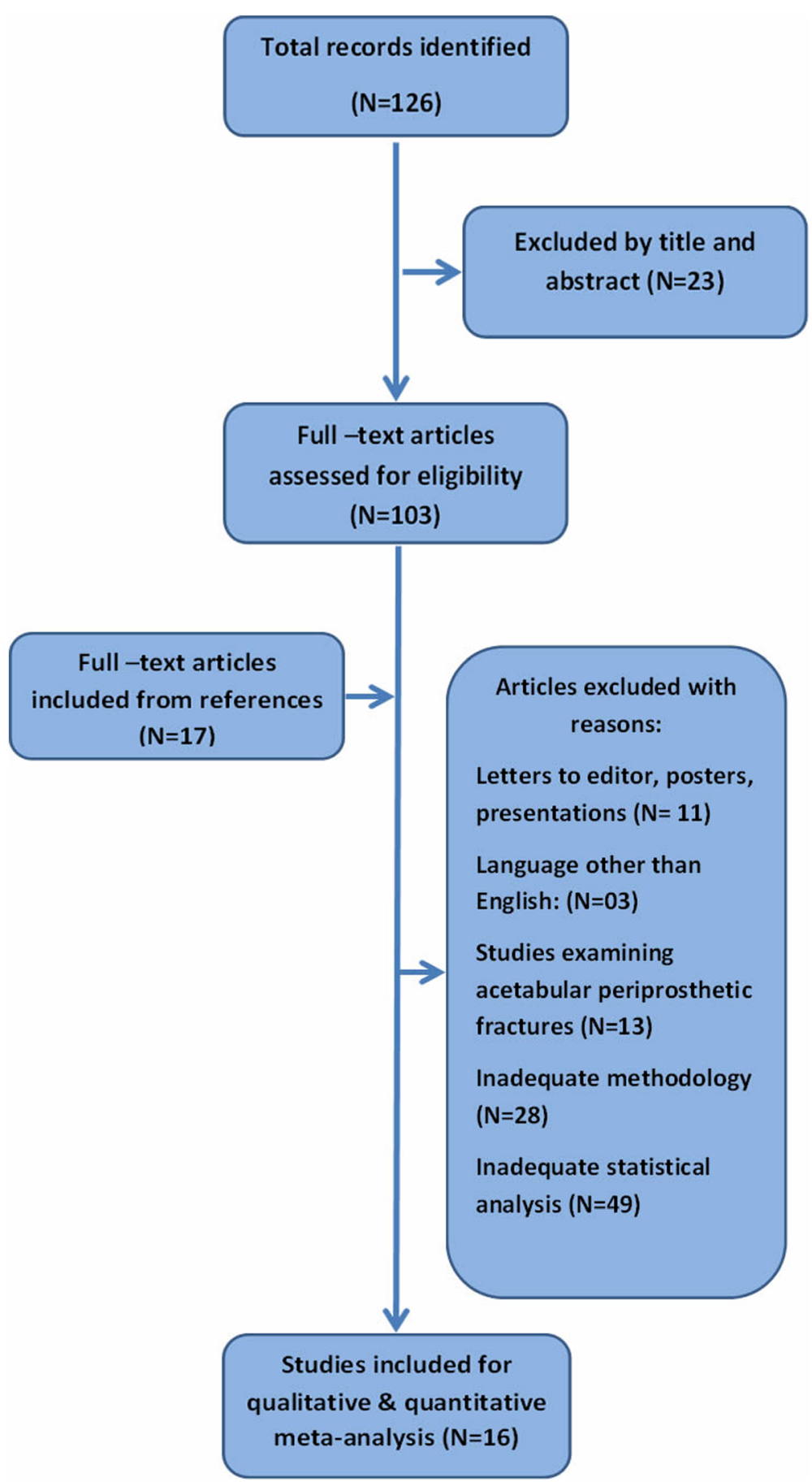

Fig. 1 Preferred Reporting Items for Systematic Reviews and Meta-Analysis (PRISMA) flowchart for the screening and identification of included studies

possibility of FPFs $(0.41,95 \%$ CI: $0.19-0.62, p<0.001)$ (Fig. 7).

The impact of the implant type that was inserted during THA was also evaluated. Meta-analysis of four [19$21,23]$, two [20, 21], three [19-21], and two [20, 21] studies regarding Exeter (Stryker, Kalamazoo, USA) $(Q=$
17.1, $I^{2}=82.5 \%, p=0.001$ ), Thompson (Stryker UK Ltd., Newbury, UK) $\left(Q=0.18, I^{2}=0.0 \%, p=0.672\right)$, Lubinus (Waldemar Link $\mathrm{GmbH} \& \mathrm{Co}$, Hamburg, Germany) $\left(Q=0.0, I^{2}=0.0 \%, p>0.999\right)$, and Biomet (Zimmer Biomet Holdings, Warsaw, USA) $\left(Q=0.0, I^{2}=\right.$ $0.0 \%, p>0.999)$ prosthesis, respectively, indicated that 


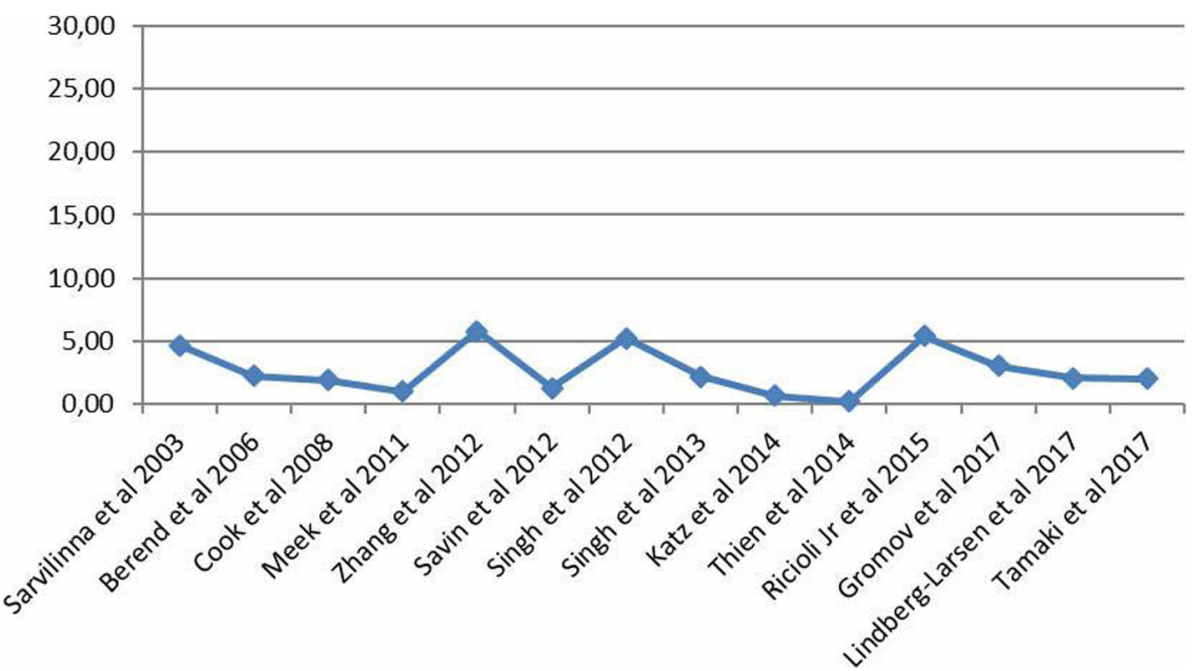

Fig. 2 Diagram demonstrating the incidence of the collected reported femoral periprosthetic fractures after hip arthroplasty between 2003 and 2017

Thompson (OR: $0.25,95 \%$ CI: $0.00-0.61, p=0.010$ ) (Fig. 8) and Biomet (OR: 0.32, 95\% CI: 0.00-0.83, $p=$ 0.021) (Fig. 9) prostheses were associated with reduced risk of FPFs. Conversely, Exeter (OR: 0.97, 95\% CI: $0.03-1.91, p=0.759$ ) and Lubinus (OR: $1.02,95 \%$ CI: $0.90-1.14, p=0.869$ ) implants did not favor the development of FPFs.

\section{Discussion}

Femoral periprosthetic fractures after HA constitute a major complication and are usually associated with increased mortality rate and inadequate functional recovery [38]. However, the general and local risk factors that contribute in the development of FPFs remain relatively unclear. This meta-analysis focused on the examination of the incidence and the detection of possible predisposing factors leading to FPFs.

Our analysis indicated that the prevalence of FPFs after HA was $0.71 \%$. Interestingly, during the last 4 years the frequency of FPFs was limited to $0.27 \%$. The reported incidences range from 0.3 to $27.8 \%$ after primary HA and from 0.3 to $17.6 \%$ after revision HAs $[3,39,40]$. Despite the fact that a growing rate of HA was noted [39], the incidence of FPFs was reduced. The progressive identification of risk factors, the advancing orthopedic education in hip surgical techniques, and the ongoing surgical experience may explain the above finding.

The frequency of FPFs was higher after the insertion of uncemented HA ranging from 3 to $18 \%[14,40,41]$. This is in line with our findings, where cemented

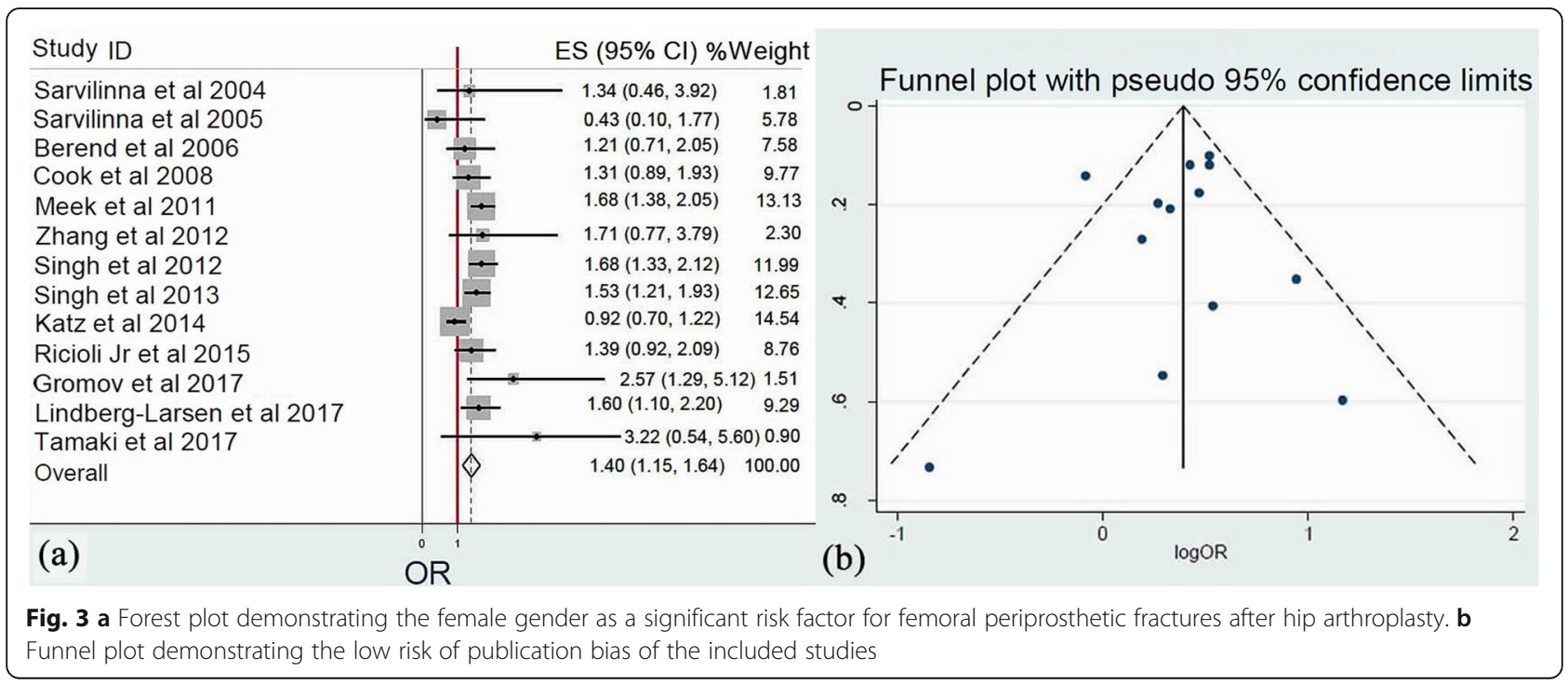




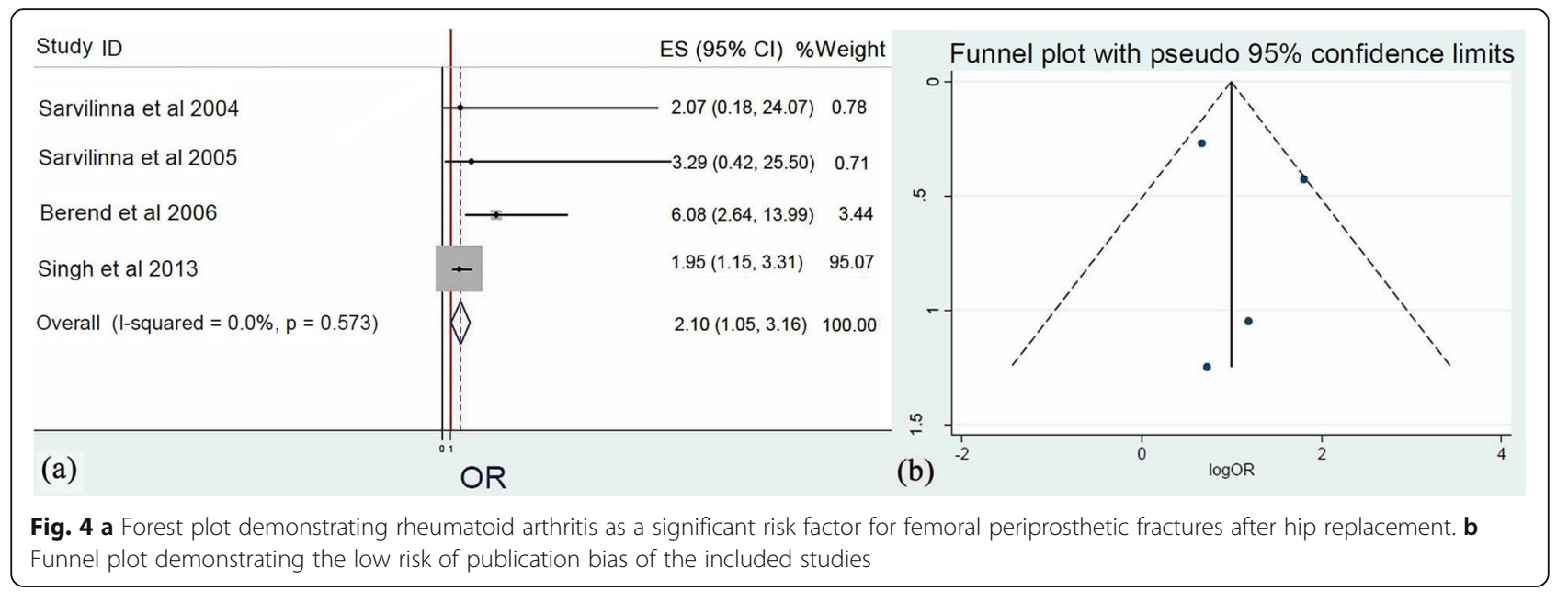

prosthesis was a protective factor for FPFs. Our observations confirmed Berry's report who observed an increased frequency of $20.9 \%$ for intra-operative fractures when using of uncemented fixation, compared with $3.6 \%$ for cemented femoral revisions [3]. Similarly, only a $3 \%$ of intra-operative FPFs were noted after the insertion of cemented implants [42], being three times less common compared with uncemented stems [43]. The above result may be explained by the fact that the insertion of cement into a weak osteoporotic femur stabilizes the bony structure and enhances the bone biomechanical properties [40]. Additionally, failure of the bone biological ingrowth or ongrowth process or occurrence of a femoral crack and microfracture during the insertion of a pressfit cementless prosthesis may lead to increased rate of FPFs even after low-energy trauma. Although the impact of implant type has been examined in many surveys, the results vary from study to study [22, 23]. Inadequate surgical familiarity with the uncemented technique and different methodological protocols (e.g., population samples or follow-up duration) could be correlated with these discrepancies.

Based on our results, revision HA was strongly associated with FPFs, a consistent result in many surveys [3, $14,44,45]$. The insertion of a new femoral stem in a weak proximal femur due to excessive osteopenia or osteoporosis, accompanied by concurrent development of intra-operative stress shielding or cortical injuries during the removal process of the previous stem or cement and the application of longer or larger-diameter stems, especially using reaming procedure, may provide an explanation for the above findings [44, 45].

Little is known about the association between femoral implant design characteristics and the frequency of FPFs. Our results did not confirm the previously reported correlation of Exeter prosthesis to increased rate of FPFs [46]. Conversely, insertion of Exeter and Lubinus prostheses did not increase the prevalence of FPFs, whereas Thompson and Biomet implants significantly decreased the incidence of FPFs (by $75 \%$ and $68 \%$, respectively).

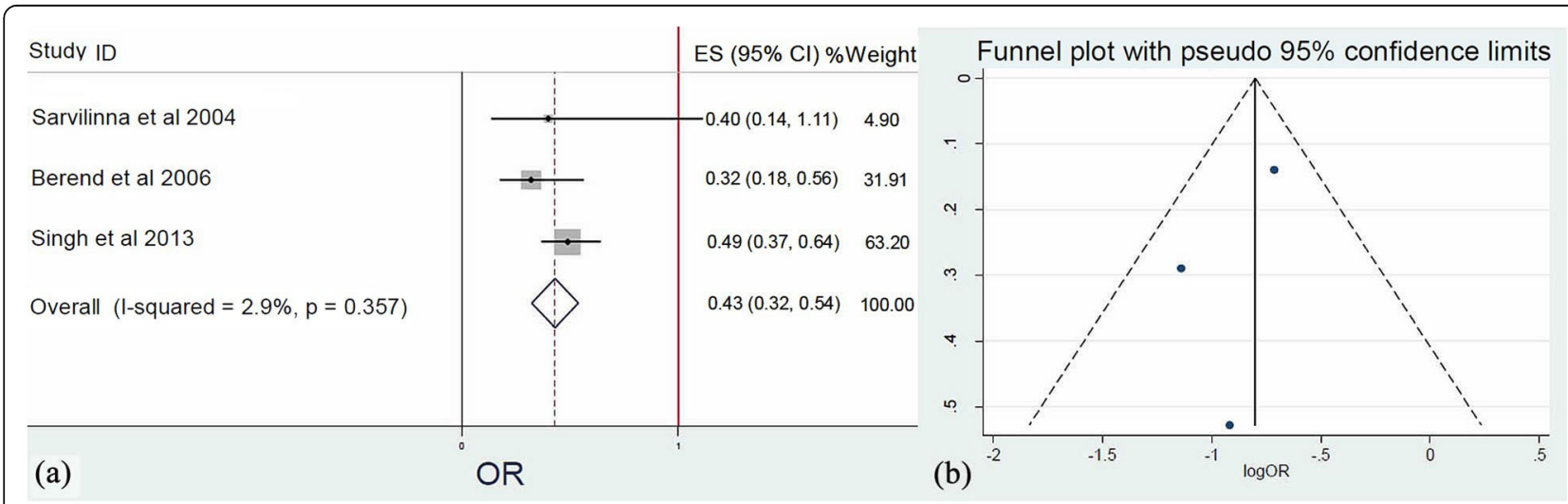

Fig. 5 a Forest plot demonstrating osteoarthritis as a significant protective factor for femoral periprosthetic fractures after hip arthroplasty. $\mathbf{b}$ Funnel plot demonstrating the low risk of publication bias of the included studies 


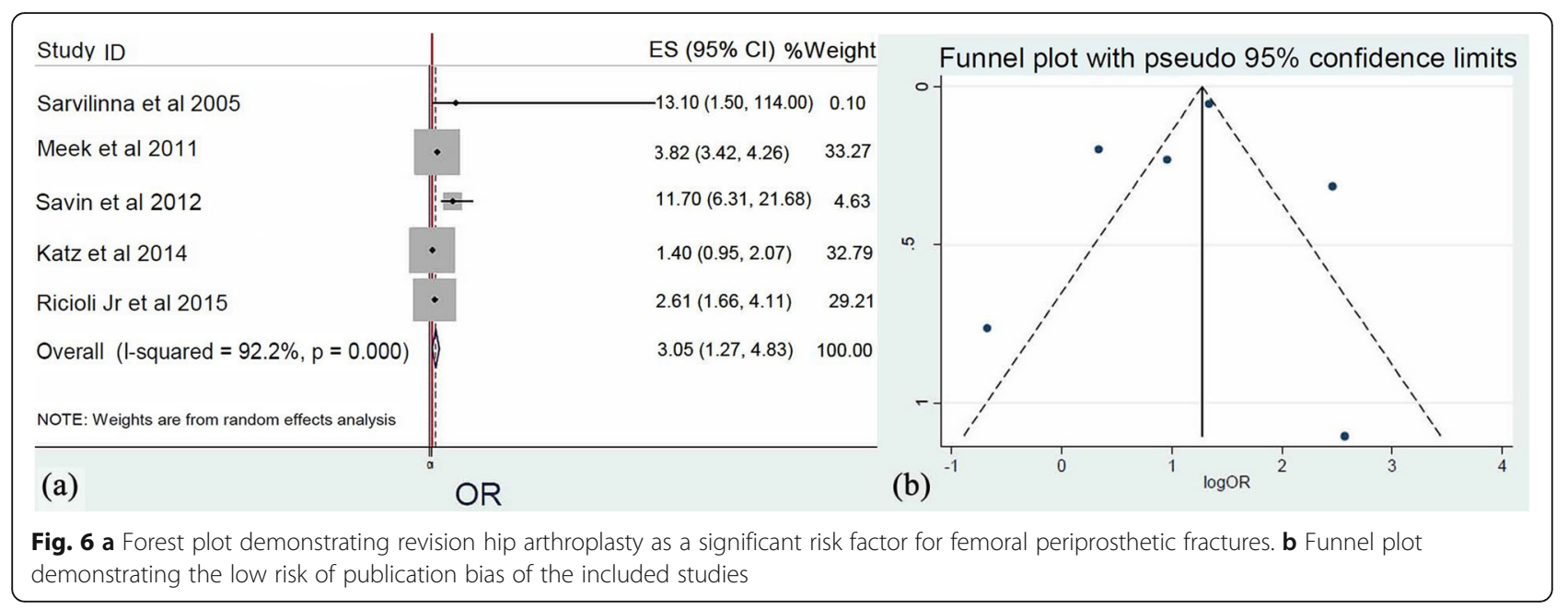

Sarvilinna et al. reported that in patients with hip fractures treated with HA, the polished wedge type of prosthesis was linked to an increased risk of FPFs [21]. Results from a large Norwegian Hip Fracture Register, which were undertaken in patients with a femoral neck fracture, demonstrated high re-operation ratio due to FPFs after the application of polished stems compared to anatomical and straight stems [47]. This is, also, consistent with a UK National Joint Registry study which investigated revision interventions for FPFs after THAs and found lower incidence of FPFs with a Charnley stem [48]. Finally, a large retrospective cohort study conducted by the UK National Joint registry after the analysis of 299,019 primary THAs reported that the high rate of FPFs after the insertion of polished hip cemented stems was, also, associated with cobalt-chromium stem material, the increased stem offset, the ovaloid and round diaphyseal cross-sectional stem shape, and the increased head size [49].
Our results showed that $\mathrm{OA}$ was a protective factor in FPF appearance, while RA was a significant risk factor being in line with previous studies [4, 14, 40, 44, 45]. Poor bone quality, multiple joint involvement and considerable comorbidity, may explain why the presence of RA was associated with a high risk of FPFs. Furthermore, the significant bone erosion, osteolytic defects, and the simultaneous induced expression of osteoclasts and inflammatory cytokines may result in the generation of FPFs [50]. Clinical studies also confirmed the close association between low Bone Mineral Density (BMD) and RA leading to increased bone loss and femoral frailty $[51,52]$. It was suggested that prevention of late FPFs could be accomplished by the intra-operative recognition of locations of cortical defects and osteolytic lesions and the prophylactically application of cortical grafts to reinforce cortical weakness and other stress risers [15]. Contrariwise, the exact mechanism of OA-protective effects in the appearance of FPFs is largely unknown.

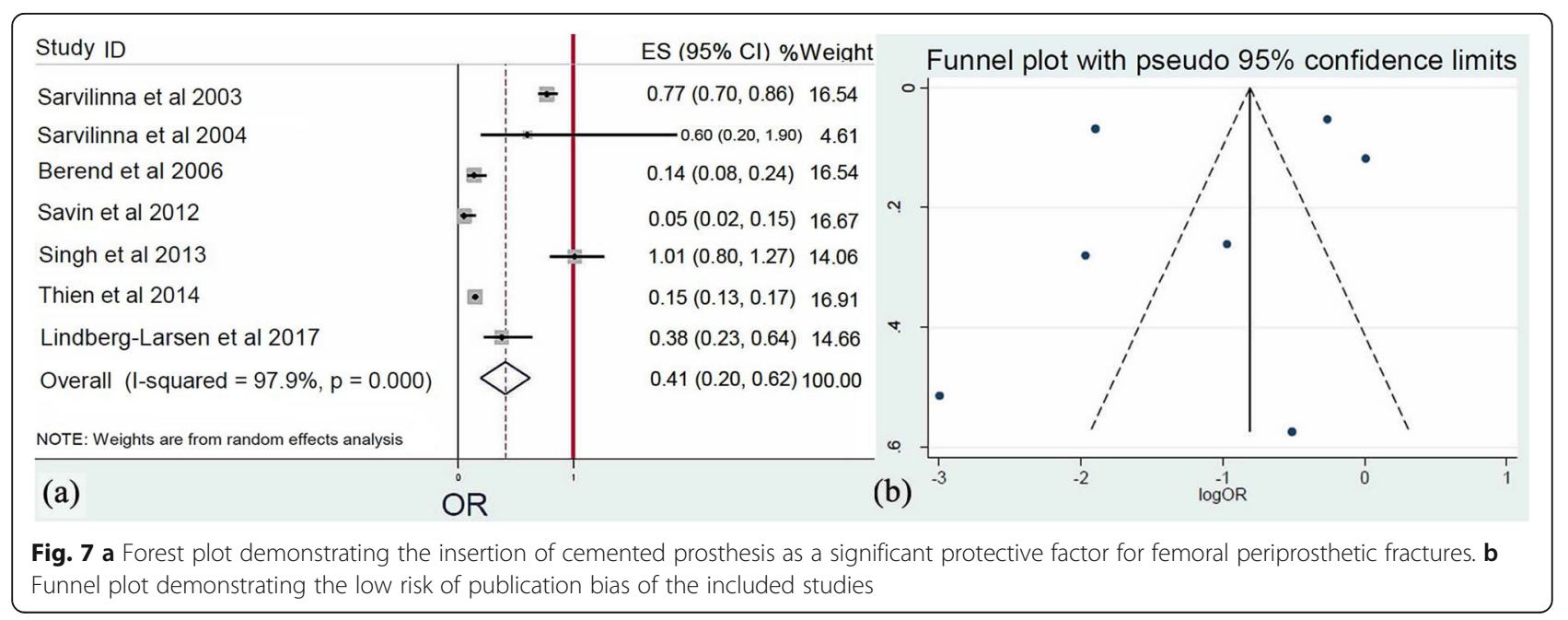




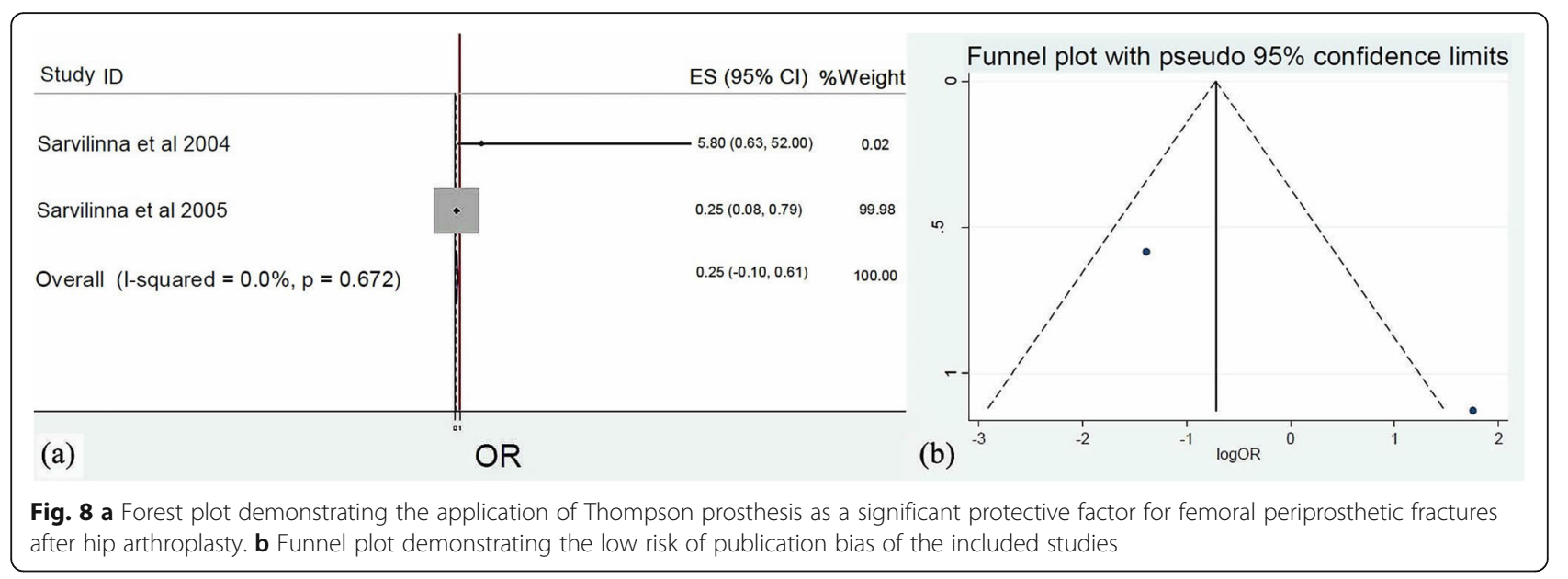

Patients with OA are characterized by reduced level of activity due to localized arthralgia and limitation of joint movements, especially to those who were overweight. Furthermore, altered embiomechanical bony structure due to subchondral sclerosis and absence osteoporotic defects may provide an extra explanation of this finding in $\mathrm{OA}$ [53].

Based on our findings, female gender was an important epidemiological factor that increased the risk of FPFs by $40 \%$. Although female gender has been suggested to be an independent risk factor, it is obviously confounded by osteoporosis [45]. Contrariwise, age older than 70 or 80 years, obesity, medical comorbidities such as cardiac disease, or physical condition with ASA score $\geq 3$ were not related with high rate of FPFs, confirming the results of previous studies [14, 40].

\section{Strengths and limitations}

Strength of our analysis was that it included all the current international literature comprising a large number of prospective studies and a large population sample (8 times larger than in previous analyses) [14, 15]. However, the selected studies had the following limitations: First, the prevalence of FPFs was calculated by a pool that included both hemiarthroplasties and THAs patients. However, in the international literature, a large number of studies that examined the risk factors, the outcomes, and the frequency of FPFs have enrolled patients of both interventions [54, 55]. Moreover, the fact that the mean incident of complications, including FPFs, did not differ significantly between patients treated with hemiarthroplasty or THAs $[4,56]$ does not alter the credibility of our results. Another limitation may was the fact that only studies written in English were reviewed and thus some studies may be missing in the analysis. Nevertheless, the vast majority of critical reviews and meta-analyses on the international literature follow the same methodology. Additional drawbacks could be the heterogeneity of data population, the variability of diagnostic and treatment protocols, the different selection criteria and follow-up periods, and the absence of

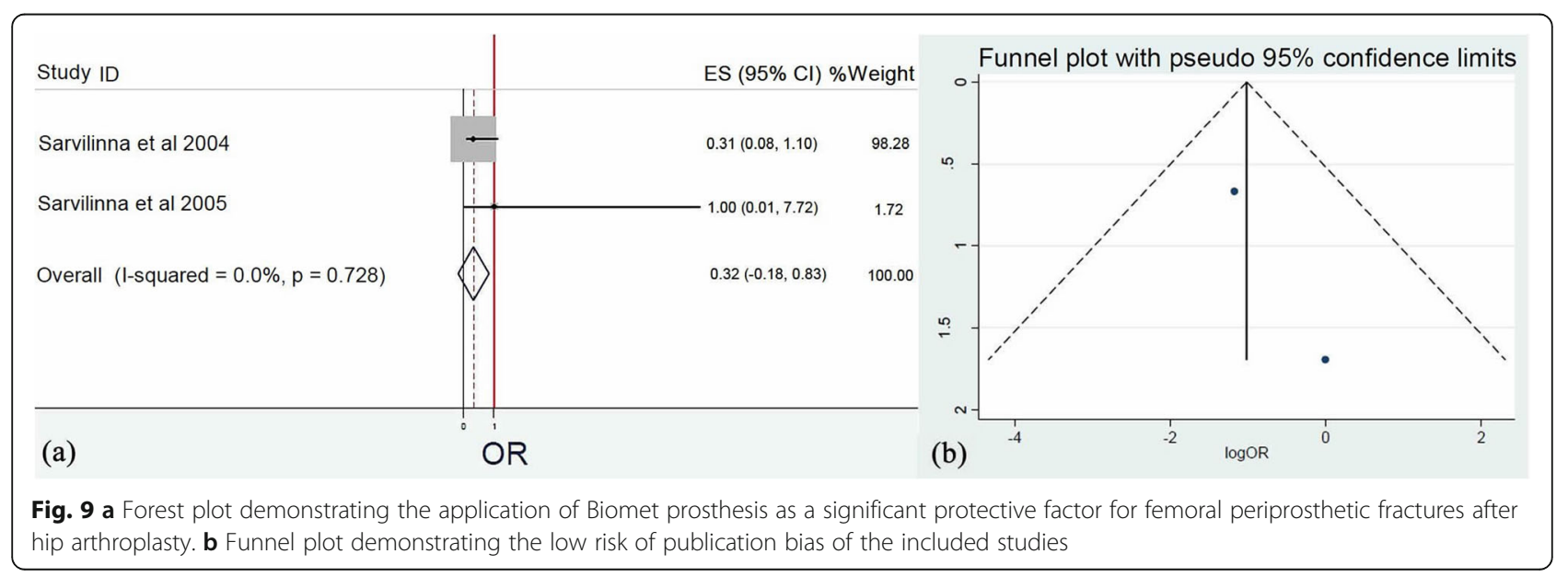


diseases severity classification (e.g., in OA). Finally, other limitation factors were the differences in methodological approaches and the conditions under which the studies were conducted or other confounding factors that were not taken into consideration.

\section{Conclusions}

This meta-analysis suggested that female gender, RA, and revision arthroplasty are major risk factors for the development of FPFs whereas OA, cement application, and insertion of Biomet or Thompson's prosthesis were correlated with low prevalence of FPFs. Obesity, cardiac diseases, advanced age, poor general health (ASA grade $\geq 3$ ), and use of Exeter or Lubinus prosthesis did not conduce to the appearance of FPFs. Based on the metaanalysis data, it could be recommended that (a) insertion of a femoral implant designed with anatomic characteristics can reduce the risk of re-operation in patients of similar age, sex, and bone quality; (b) intra-operative application of cortical grafts may prevent possible bone defects or stress risers in patients with known risk factors like RA or revision surgery [15]; (c) cement insertion for the fixation of the femoral implant is suggested to reduce the risk of FPFs; (d) systematic clinical and radiographic postoperative follow-ups are necessary to examine the stem stability and bone quality; and (e) the pre- and postoperative nutritional status and BMD level must be assessed and corrected, especially in patients suffering of RA. However, the risk of atypical femoral neck fractures after prolonged bisphosphonate therapy should be considered [57].

Future basic science and clinical prospective studies are warranted to establish stronger evidence regarding the mechanisms that alter bone strength and quality in female patients and in those suffering of rheumatic diseases resulting in FPFs, to strengthen the efficacy of insertion of Biomet or Thompson's prostheses though cemented procedure in the prevention of FPFs and to produce more robust results for the clarification of the potential risk factors contributing to the development of FPFs after HAs.

\section{Supplementary Information}

The online version contains supplementary material available at https://doi. org/10.1186/s13018-020-02152-0.

Additional file 1: Supplemental Table 1. PRISMA checklist

\section{Abbreviations}

ASA: American Society of Anaesthesiologists; 95\% Cl: 95\% confidence intervals; FPFs: Femoral periprosthetic fractures; HA: Hip arthroplasties; ICTRP: International Clinical Trials Registry platform; OA: Osteoarthritis; ORs: Odds ratios; PRISMA: Preferred Reporting Items for Systematic Reviews and Meta-Analysis; RA: Rheumatoid arthritis; THA: Total hip arthroplasty; WHO: World Health Organization

\section{Acknowledgements}

Not applicable

\section{Authors' contributions}

CB conceived the idea; performed the study design, data collection, data analysis; and wrote the manuscript. AK performed the data analysis and wrote the manuscript. AK performed the data collection and data analysis and edited the manuscript. KP performed the data analysis and edited the manuscript. NN performed the data collection and data analysis and edited the manuscript. KB performed the data analysis and edited the manuscript. PJP performed the data analysis and edited the manuscript. ODS performed the data collection and data analysis and edited the manuscript. The authors read and approved the final manuscript.

\section{Funding}

Not applicable

Availability of data and materials

Datasets are available through the corresponding author upon reasonable request

Ethics approval and consent to participate

Not applicable

Consent for publication

Not applicable

\section{Competing interests}

The authors declare that they have no conflicts of interest.

\section{Author details}

'Department of Orthopaedic Surgery, Naval Hospital of Athens, Deinokratous 70, 11521 Athens, Greece. ${ }^{2}$ Laboratory of Molecular Pharmacology/Division for Orthopaedic Research, School of Health Sciences, University of Patras, 26504 Patras, Greece. ${ }^{3}$ Sonnenhof Spital, Bern, Switzerland. ${ }^{4} 1$ st Department of Orthopaedic Surgery, School of Medicine, National and Kapodistrian University of Athens, "ATTIKON" University General Hospital, 12462 Athens, Greece.

Received: 3 November 2020 Accepted: 9 December 2020 Published online: 06 January 2021

\section{References}

1. Rayan F, Haddad F. Periprosthetic femoral fractures in total hip arthroplasty - a review. Hip Int. 2010;20(4):418-26.

2. Lindahl H, Malchau H, Herberts $P$, Garellick G. Periprosthetic femoral fractures classification and demographics of 1049 periprosthetic femoral fractures from the Swedish National Hip Arthroplasty Register. J Arthroplasty. 2005;20(7):857-65.

3. Berry DJ. Epidemiology: hip and knee. Orthop Clin North Am. 1999;30(2): 183-90.

4. Lindahl $\mathrm{H}$. Epidemiology of periprosthetic femur fracture around a total hip arthroplasty. Injury. 2007;38(6):651-4.

5. Della Rocca GJ, Leung KS, Pape HC. Periprosthetic fractures: epidemiology and future projections. J Orthop Trauma. 2011;25(Suppl 2):S66-70.

6. Füchtmeier B, Galler M, Müller F. Mid-term results of 121 periprosthetic femoral fractures: increased failure and mortality within but not after one postoperative year. J Arthroplasty. 2015;30(4):669-74.

7. Beals RK, Tower SS. Periprosthetic fractures of the femur. An analysis of 93 fractures. Clin Orthop Relat Res. 1996;327:238-46.

8. Lindahl $H$, Garellick $G$, Regnér $H$, Herberts $P$, Malchau $H$. Three hundred and twenty-one periprosthetic femoral fractures. J Bone Joint Surg Am. 2006; 88(6):1215-22

9. Bhattacharyya T, Chang D, Meigs JB, Estok DM 2nd, Malchau H. Mortality after periprosthetic fracture of the femur. J Bone Joint Surg Am. 2007;89(12): 2658-62.

10. Mediouni M. A new generation of orthopaedic surgeons: "T-model". Curr Orthop Pract. 2019:30(5):444-5.

11. Mediouni M, Madiouni R, Gardner M, Vaughan N. Translational medicine: challenges and new orthopaedic vision (Mediouni-Model). Curr Orthop Pract. 2020;31(2):196-200. 
12. Mediouni M, Schlatterer DR, Madry H, Cucchiarini M, Rai B. A review of translational medicine. The future paradigm: how can we connect the orthopaedic dots better? Curr Med Res Opin. 2018;34(7):1217-29.

13. Deng $Y$, Kieser D, Wyatt M, Stringer M, Frampton C, Hooper G. Risk factors for periprosthetic femoral fractures around total hip arthroplasty: a systematic review and meta-analysis. ANZ J Surg 2020;90(4):441-7.

14. Zhu Y, Chen W, Sun T, Zhang X, Liu S, Zhang Y. Risk factors for the periprosthetic fracture after total hip arthroplasty: a systematic review and meta-analysis. Scand J Surg. 2015;104(3):139-45.

15. Franklin J, Malchau H. Risk factors for periprosthetic femoral fracture. Injury. 2007;38(6):655-60.

16. Moher D, Liberati A, Tetzlaff J. Altman DG; PRISMA Group. Preferred reporting items for systematic reviews and meta-analyses: the PRISMA statement. Int J Surg. 2010;8(5):336-41.

17. Merola M, Affatato S. Materials for hip prostheses: a review of wear and loading considerations. Materials (Basel). 2019;12(3):495

18. Frenzel S, Vécsei $V$, Negrin L. Periprosthetic femoral fractures--incidence, classification problems and the proposal of a modified classification scheme. Int Orthop. 2015;39(10):1909-20.

19. Wells GA, Shea B, O'Connell D, Peterson J, Welch V, Losos M, Tugwell P. The Newcastle-Ottawa Scale (NOS) for assessing the quality of nonrandomized studies in meta-analysis. 2011. Available from: www.ohri.ca/programs/ clinical_epidemiology/oxford.asp (cited 15 October 2019).

20. Sarvilinna R, Huhtala HS, Sovelius RT, Halonen PJ, Nevalainen JK, Pajamäki KJ. Factors predisposing to periprosthetic fracture after hip arthroplasty: a case ( $n=31$ )-control study. Acta Orthop Scand. 2004;75(1):16-20.

21. Sarvilinna R, Huhtala H, Pajamäki J. Young age and wedge stem design are risk factors for periprosthetic fracture after arthroplasty due to hip fracture. A case-control study. Acta Orthop. 2005;76(1):56-60.

22. Berend ME, Smith A, Meding JB, Ritter MA, Lynch T, Davis K. Long-term outcome and risk factors of proximal femoral fracture in uncemented and cemented total hip arthroplasty in 2551 hips. J Arthroplasty. 2006; 21(6 Suppl 2):53-9.

23. Cook RE, Jenkins PJ, Walmsley PJ, Patton JT, Robinson CM. Risk factors for periprosthetic fractures of the hip: a survivorship analysis. Clin Orthop Relat Res. 2008:466(7):1652-6.

24. Meek RM, Norwood T, Smith R, Brenkel IJ, Howie CR. The risk of periprosthetic fracture after primary and revision total hip and knee replacement. J Bone Joint Surg Br. 2011;93(1):96-101.

25. Zhang C. Analysis on relevant factors of around prosthesis fracture after total replacement. Mod Prev Med. 2012;39:3961-3.

26. Savin L, Barhăroşie C, Botez P. Periprosthetic femoral fractures--evaluation of risk factors. Rev Med Chir Soc Med Nat lasi. 2012;116(3):846-52.

27. Singh JA, Jensen MR, Lewallen DG. Patient factors predict periprosthetic fractures after revision total hip arthroplasty. J Arthroplasty. 2012;27(8): 1507-12.

28. Singh JA, Jensen MR, Harmsen SW, Lewallen DG. Are gender, comorbidity, and obesity risk factors for postoperative periprosthetic fractures after primary total hip arthroplasty? J Arthroplasty. 2013; 28(1):126-131.e1-2.

29. Katz JN, Wright EA, Polaris JJ, Harris MB, Losina E. Prevalence and risk factors for periprosthetic fracture in older recipients of total hip replacement: a cohort study. BMC Musculoskelet Disord. 2014;15:168.

30. Thien TM, Chatziagorou G, Garellick G, Furnes O, Havelin LI, Mäkelä K, Overgaard S, Pedersen A, Eskelinen A, Pulkkinen P, Kärrholm J. Periprosthetic femoral fracture within two years after total hip replacement: analysis of 437,629 operations in the nordic arthroplasty register association database. J Bone Joint Surg Am. 2014;96(19):e167.

31. Ricioli W Jr, Queiroz MC, Guimarães RP, Honda EK, Polesello G, Fucs PM. Prevalence and risk factors for intra-operative periprosthetic fractures in one thousand eight hundred and seventy two patients undergoing total hip arthroplasty: a cross-sectional study. Int Orthop. 2015;39(10):1939-43.

32. Gromov K, Bersang A, Nielsen CS, Kallemose T, Husted H, Troelsen A. Risk factors for post-operative periprosthetic fractures following primary total hip arthroplasty with a proximally coated double-tapered cementless femoral component. Bone Joint J. 2017;99-B(4):451-7.

33. Lindberg-Larsen M, Jørgensen CC, Solgaard S, Kjersgaard AG, Kehlet H. Increased risk of intraoperative and early postoperative periprosthetic femoral fracture with uncemented stems. Acta Orthop. 2017:88(4):390-4

34. Tamaki T, Jonishi K, Miura Y, Oinuma K, Shiratsuchi H. Cementless taperedwedge stem length affects the risk of periprosthetic femoral fractures in direct anterior total hip arthroplasty. J Arthroplasty. 2018;33(3):805-9.
35. Wells GA, Shea B, O'Connell D, et al. The Newcastle-Ottawa Scale (NOS) for assessing the quality of nonrandomized studies in meta-analyses. Ottawa Health Research Institute. 2000. http://www.ohri.ca/programs/clinical_ epidemiology/oxford.htm (date last accessed 15 October 2019). Google Scholar.

36. Oremus $M$, Wolfson C, Perrault A, Demers L, Momoli F, Moride $Y$. Interrater reliability of the modified Jadad quality scale for systematic reviews of Alzheimer's disease drug trials. Dement Geriatr Cogn Disord. 2001;12(3):232-6

37. Bown MJ, Sutton AJ. Quality control in systematic reviews and metaanalyses. Eur J Vasc Endovasc Surg. 2010;40(5):669-77.

38. Lee SR, Bostrom MP. Periprosthetic fractures of the femur after total hip arthroplasty. Instr Course Lect. 2004;53:111-8.

39. Maradit Kremers $H$, Larson DR, Crowson CS, Kremers WK, Washington RE, Steiner CA, Jiranek WA, Berry DJ. Prevalence of total hip and knee replacement in the United States. J Bone Joint Surg Am. 2015;97(17): 1386-97.

40. Sidler-Maier CC, Waddell JP. Incidence and predisposing factors of periprosthetic proximal femoral fractures: a literature review. Int Orthop. 2015;39(9):1673-82.

41. Foster AP, Thompson NW, Wong J, Charlwood AP. Periprosthetic femoral fractures--a comparison between cemented and uncemented hemiarthroplasties. Injury. 2005;36(3):424-9.

42. Morrey BF, Kavanagh BF. Complications with revision of the femoral component of total hip arthroplasty. Comparison between cemented and uncemented techniques. J Arthroplasty. 1992;7(1):71-9.

43. Abdel MP, Houdek MT, Watts CD, Lewallen DG, Berry DJ. Epidemiology of periprosthetic femoral fractures in 5417 revision total hip arthroplasties: a 40-year experience. Bone Joint J. 2016;98-B(4):468-74.

44. Davidson D, Pike J, Garbuz D, Duncan CP, Masri BA. Intraoperative periprosthetic fractures during total hip arthroplasty. Evaluation and management. J Bone Joint Surg Am. 2008:90(9):2000-12.

45. Mayle RE, Della Valle CJ. Intra-operative fractures during THA: see it before it sees us. J Bone Joint Surg Br. 2012;94(11 Suppl A):26-31.

46. Garellick G, Malchau H, Regnér H, Herberts $P$. The Charnley versus the Spectron hip prosthesis: radiographic evaluation of a randomized, prospective study of 2 different hip implants. J Arthroplasty. 1999;14(4):414-25.

47. Kristensen TB, Dybvik E, Furnes O, Engesæter LB, Gjertsen JE. More reoperations for periprosthetic fracture after cemented hemiarthroplasty with polished taper-slip stems than after anatomical and straight stems in the treatment of hip fractures: a study from the Norwegian Hip Fracture Register 2005 to 2016. Bone Joint J. 2018;100-B(12):1565-71.

48. Palan J, Smith MC, Gregg P, Mellon S, Kulkarni A, Tucker K, Blom AW, Murray DW, Pandit $H$. The influence of cemented femoral stem choice on the incidence of revision for periprosthetic fracture after primary total hip arthroplasty: an analysis of national joint registry data. Bone Joint J. 2016;98$B(10): 1347-54$

49. Lamb JN, Jain S, King SW, West RM, Pandit HG. Risk factors for revision of polished taper-slip cemented stems for periprosthetic femoral fracture after primary total hip replacement: a registry-based cohort study from the National Joint Registry for England, Wales, Northern Ireland and the Isle of Man. J Bone Joint Surg Am. 2020;102(18):1600-8.

50. Wei S, Siegal GP. Mechanisms modulating inflammatory osteolysis: a review with insights into therapeutic targets. Pathol Res Pract. 2008; 204(10):695-706.

51. Hu Z, Xu S, Lin H, Ni W, Yang Q, Qi J, Du K, Gu J, Lin Z. Prevalence and risk factors for bone loss in Southern Chinese with rheumatic diseases. BMC Musculoskelet Disord. 2020;21(1):416.

52. Wysham KD, Shoback DM, Andrews JS, Katz PP. Sex differences in frailty and its association with low bone mineral density in rheumatoid arthritis. Bone Rep. 2020;12:100284

53. Mann T, Eisler T, Bodén H, Muren O, Stark A, Salemyr M, Sköldenberg O. Larger femoral periprosthetic bone mineral density decrease following total hip arthroplasty for femoral neck fracture than for osteoarthritis: a prospective, observational cohort study. J Orthop Res. 2015;33(4):504-12.

54. Naqvi GA, Baig SA, Awan N. Interobserver and intraobserver reliability and validity of the Vancouver classification system of periprosthetic femoral fractures after hip arthroplasty. J Arthroplasty. 2012;27(6):1047-50.

55. Moreta J, Aguirre U, de Ugarte OS, Jáuregui I, Mozos JL. Functional and radiological outcome of periprosthetic femoral fractures after hip arthroplasty. Injury. 2015;46(2):292-8. 
56. McGraw IW, Spence SC, Baird EJ, Eckhardt SM, Ayana GE. Incidence of periprosthetic fractures after hip hemiarthroplasty: are uncemented prostheses unsafe? Injury. 2013;44(12):1945-8.

57. Kim KK, Park YW, Kim TH, Seo KD. Atypical femoral neck fracture after prolonged bisphosphonate therapy. J Pathol Transl Med. 2020;12:100284.

\section{Publisher's Note}

Springer Nature remains neutral with regard to jurisdictional claims in published maps and institutional affiliations.

Ready to submit your research? Choose BMC and benefit from:

- fast, convenient online submission

- thorough peer review by experienced researchers in your field

- rapid publication on acceptance

- support for research data, including large and complex data types

- gold Open Access which fosters wider collaboration and increased citations

- maximum visibility for your research: over $100 \mathrm{M}$ website views per year

At $B M C$, research is always in progress.

Learn more biomedcentral.com/submissions 